his experience in Salonika as an example.

On returning to the Brown Institution after the war, he made a series of incubators in which virus cultures rotated while intermittently illuminated through prisms and off mineral crystals. In a letter to an editor who was puzzled, as the Medical Research Council was and as the reader will be, about the function of this gallimaufry, he said he was not trying to create life. The design was, however, logically based on his ideas of conditions on Earth when life started. In an article in 1949, and a letter in 1950, he said he had been getting results. In various places he used such phrases as "precellular life", "selfproliferating enzyme" and "living protoplasm that forms no definite individuals". Unfortunately, he did not describe the evidence. It would be a useful guide in planning research along similar lines: Twort's ideas may deserve more attention than they have been given.

Towards the end of his life he wrote hundreds of letters to newspapers and journals. Most of them were not published. Because of his tendency to mistake foolishness for malignity, they were often strident. Some editors' rejection letters, especially one from the Lancet, gave gentle advice: he sometimes took it and achieved publication.

Antony Twort designed the biography as a story about his father, rather than a thesis on his research. Most of it is therefore concerned with family matters and hobbies. So it would be unfair to criticize the results because the scientific material is sometimes unclear: a more systematic system of dating and identifying the many letters quoted would be welcome. There is no complete list of F. W. Twort's publications. In this respect, Twort has been ill-served: the Royal Society obituary does not give a complete list either.

N. W. Pirie is at Rothamsted Experimental Station, AFRC Institute of Arable Crops Research, Harpenden, Hertfordshire AL5 2JQ, UK.

\title{
Through the clouds of obscurity
}

\section{Robert Hutchison}

Stardust to Planets: A Geological Tour of the Solar System. By Harry Y. McSween. St Martin's: 1993. Pp. 241. \$22.95.

MosT books on the Solar System cover the Sun, terrestrial planets, outer planets, asteroids and comets in some preordained order. By contrast, "the origin and geologic evolution of the solar system around us" are refreshingly covered in this disordered but unique series of 15 essays. The book will provide new students or amateurs with a broad overview of this complex subject. And it is a joy to read, partly because of the simple language and partly because each chapter is selfcontained.

McSween makes it clear that he has not tried to be comprehensive in his overview: he does not wish to swamp the mind of the nonspecialist. Instead, he stops at different objects in the Solar System so as to "focus on some geologic materials, phenomena or processes", thereby killing groups of several different birds with single stones. Thus the second chapter covers the history of astronomy, superposition of strata, photogeology and absolute age determination, all as applied to the Moon. "Hardened hearts" covers not only the "cores and mantles of the terrestrial planets" but seismology, magnetism (or the lack of it), convection (as "in your morning cup of coffee") and the identity of the light element in the Earth's core. In the essay on Mars we are shown that a planet's volcanic activity depends on its size, and learn about atmospheric gases and the origin of excess radiogenic argon. Fundamental problems and principles are simply and lucidly discussed.

For about 30 years we have known that meteorites contain matter that had 'recently' ( 4.6 billion years ago!) been processed in stars, but the separation of 'stardust' in the laboratory was achieved only in the mid-1980s. This exciting story is told by the author from first-hand experience: he is actively engaged in the study of chondrites, the meteorites that brought the dust from stars, unscathed, to Earth. McSween uses this chapter to portray the variety of stars and their different fates. Other aspects of astrophysics are dealt with elsewhere: orbital dynamics, the origin of comets, major impacts and the cosmic abundances of the elements are just a few of the subjects discussed using snapshots of different objects in the Solar System. For the origin of life, however, only the Earth will do.

As a North American, McSween tends to use analogues and anecdotes that may be lost on some readers. But the clarity of the scientific prose more than compensates for the US idiom. The figures and diagrams are adequate, but not spectacular (there is no colour). McSween has given us an up-to-date view through the clouds of Venus and the scientific jargon that equally obscure Solar System studies from the nonscientist. Anyone with scientific curiosity will enjoy the tour.

Robert Hutchison is in the Department of Mineralogy, Natural History Museum, Cromwell Road, London SW7 5BD, UK.

\section{On the edge}

\author{
Gabriel A. Dover
}

The Origins of Order: Self-Organization and Selection in Evolution. By Stuart A. Kauffman. Oxford University Press: 1993. Pp. 709. \$75, £55 (hbk); \$29.95, $£ 17.95$ (pbk).

Ground Control to Major Tom

Your circuit's dead, there's something wrong

Can you hear me Major Tom

This is Major Tom to Ground Control I'm stepping through the door And I'm floating in a most peculiar way And the stars look very different today.

OuT on the edge of space, David Bowie's Major Tom* hauntingly captured the mood of the 1970s as he cut loose and drifted off. About the same time, Stuart Kauffman took his first steps into the statistical otherworldliness of random parallel-processing Boolean networks as an ensemble approach to locating the 'deep laws' governing biological evolution and ontogenetic unfolding. Twenty years on, Kauffman beckons us, in this massive exposition, to join him on the "edge of chaos" where adaptive complex systems are poised between "frozen" order and "unfrozen" chaos - the supposed global kissing-gate between natural selection and the emergent order of cybernetic systems.

The style is heady, sententious and dangerously seductive, with an audible breathlessness throughout, brought on by the structural wonders visible in nonlinear dynamical systems. It is all too easy to harken to Kauffrnan's call, to cut loose from our cherished preconceptions of evolution as a hotchpotch of frozen accidents, opportunistically and singularly fashioned by "chance caught on the wing" (to use Monod's phrase). Kauffman is fighting for the conceptual high-ground of inevitable "beautiful and elegant" deep structures, initiated during life's beginnings and "casting an image of permanence and underlying law over biology", the unavoidable "failure" not "success" of selection. Were life to "tap-dance again its erratic course", Kauffman suspects with "quiet passion that below the particular teeming molecular traffic in each cell, lie the fundamental principles of order any life would reexpress".

\section{Major Tom to Ground Control \\ Though I've passed 100,000 miles I'm feeling very still}

And I think my spaceship knows which way to go.

The Central Problem as laid out by Kauffman is that selection acting alone would have an imponderably difficult task in generating ordered, "enormously complex biological systems" simply by shifting around variant alleles in its relentless

*Lyrics by permission of Onward Music Ltd

NATURE · VOL 365 - 21 OCTOBER 1993 